\title{
Dentists willing to sacrifice higher wages to work in richer areas, study shows
}

Dentists appear happy to work for lower pay if they are based in more affluent areas as pay levels vary around the UK, according to a new report ${ }^{1}$ from Christie \& Co.

Christie \& Co, a specialist business property advisor covering various sectors including healthcare, published its first report on workforce challenges in the dental sector on 15 October 2018, focusing on the shortage of dental associates, key workforce trends, and related topics including the impact of Brexit.

Using official statistics from the likes of the General Dental Council (GDC) and the Office for National Statistics (ONS), the report says that dentist numbers have been rising steadily in the past few years from 38,379 in 2010 to 41,704 in 2017 - a 1.2\% compound annual growth rate over seven years while the UK population annual growth rate was $0.73 \%$ over the same period.

However, the supply of dentists was under pressure, particularly in Wales where there was one dentist per 1,900 people, followed by one dentist per 1,700 people in England, while Scotland and Northern Ireland had slightly better ratios at one dentist per 1,400 and 1,200 people, respectively.

The report authors said: 'Maintaining and increasing the homegrown supply pipeline of new dentists is important, particularly given uncertainties associated with Brexit and the pressure on existing resource if a greater proportion of the population were to visit a dentist more regularly.

Newly qualified dentists preferred to become associates rather than principal dentists, said the authors, and there was a growing trend for dentists to fewer hours.

A key issue highlighted in the report was the distribution of the dental workforce and the supply of good quality dental associates across all areas of the UK.

Using financial data from more than 500 dental practices and a survey of operators across England and Wales, Christie \& Co estimated associate pay rates.

It found that pay scales, as measured by average associate rates per UDA, varied significantly by region ranging from $£ 10.01$ to $£ 11.19$. The overall average for England and Wales was $£ 10.44$.

The regions with the highest pay scales were the South West, Wales and the East of England and operators identified these regions as being particularly challenging areas for recruitment, therefore suggesting that these higher rates were required to attract labour.

Associates in the West Midlands appeared to be paid the lowest rates on average, but the operator survey suggested that the Midlands represented a mixed picture. London was the second lowest paid region.
The report says: 'This research provides evidence that dentists prefer to work in affluent areas, gravitate towards cities and are willing to be paid less in order to satisfy these preferences. Such trends create pressure points in other less affluent areas with a key knock on impact being the ability of dental operators to achieve NHS targets.'

The report notes that the majority of dentists (72.2\%) who are currently registered to work in the UK also qualified in the UK.

The next largest group is dentists who qualified in the European Economic Area (EEA) (16.3\%) and the remaining dentists qualified overseas, outside of the EEA.

Over time, the number of UK qualified dentists has grown year on year since 2014 . For the same period, the number of EEA registered dentists fell for three consecutive years from 2014 to 2016 stabilising in 2017, with the total number of EEA dentists remaining flat. There have also been ongoing reductions in the total number of dentists who qualified overseas. Simon Hughes, Managing Director Medical for the firm, said: 'While the report highlights key challenges facing the dental sector and especially operators, including UDA performance, staff recruitment and retention, demand for quality practices is exceeding supply in most areas and market segments across the UK.

'With an increasing number and variety of buyers seeking opportunities in the sector, there is no doubt that the dental market landscape is changing and diversifying.'

James Richards, Head of Global Career Services Development for the $B D J$, said: 'There are shortages everywhere apart from London. Employers need to do a lot in terms of employer branding to enhance their adverts and convey why their location is a great place to live and work.

'We are seeing more and more dentists wanting to work part time and then picking up locum work as well. They want more flexibility in how they work. Full-time vacancies are harder to fill as a result.

'We've seen a rise in the amount of dentists, a rise in the amount of views to $\mathrm{BDJ}$ Jobs, and a rise in applications in affluent areas, so why are there still shortages? The main issue is how do we make the rest of the UK more attractive?'

1. Christie \& Co. The Dental Industry 2018: Staffing, Brexit and The Dentist Shortage (15 October 2018). Available at https://www.christie.com/christieMediaLibraries/christie/PDFs-Publications/ Dental/CCO-The-Dental-Industry-2018.pdf?ext=.pdf (accessed 17 October 2018). 